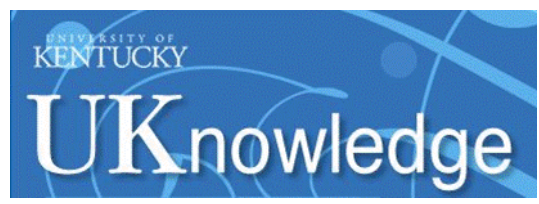

University of Kentucky

UKnowledge

Office for Policy Studies on Violence Against Women Publications

Policy Studies on Violence Against Women

$12-1984$

\title{
Violence in College Students' Dating Relationships
}

\author{
Carol K. Sigelman \\ Eastern Kentucky University \\ Carol E. Jordan-Berry \\ University of Kentucky, carol.j@uky.edu \\ Katharine A. Wiles \\ Eastern Kentucky University
}

Follow this and additional works at: https://uknowledge.uky.edu/ipsvaw_facpub

Part of the Criminal Law Commons, Criminology and Criminal Justice Commons, Family Law Commons, Law and Gender Commons, Law and Psychology Commons, Law and Society Commons, Psychology Commons, Social Work Commons, and the Sociology Commons

Right click to open a feedback form in a new tab to let us know how this document benefits you.

\section{Recommended Citation}

Sigelman, D., Jordan-Berry, C., \& Wiles, K. (1984). Violence in college students' dating relationships. Journal of Applied Social Psychology, 14(6) 53 - 548.

This Article is brought to you for free and open access by the Policy Studies on Violence Against Women at UKnowledge. It has been accepted for inclusion in Office for Policy Studies on Violence Against Women Publications by an authorized administrator of UKnowledge. For more information, please contact UKnowledge@lsv.uky.edu. 


\section{Violence in College Students' Dating Relationships}

Digital Object Identifier (DOI)

http://dx.doi.org/10.1111/j.1559-1816.1984.tb02258.x

Notes/Citation Information

Published in Journal of Applied Social Psychology, v. 14, no. 6, p. 53-548. 


\section{Violence in College Students' Dating Relationships}

\section{Carol K. Sigelman, ${ }^{2}$ Carol J. Berry, and Katharine A. Wiles Eastern Kentucky University}

In a survey of 504 college students examining predictors of violence in heterosexual relationships, over half of both men and women had committed at least one physically violent act, and men more often than women reported having been the victims of such acts. Most respondents who reported some experience with violence had both committed and received it, were involved in relatively few different types of violence, and first experienced violence when a relationship had moved beyond the casual dating stage. Modest associations between physical violence and sexual aggression were uncovered. In a series of discriminant analyses, mon who abused their partners were not readily distinguished from men who did not, but tended to be young, low in family income, traditional in attitudes toward women, abused as children, currently living with a woman, and from Appalachian areas. Women who abused were more readily discriminated and scored low in social desirability, were abused as children, and were from non-Appalachian areas. Men who were abused were likely to be living with a woman and tended to be low in family income; similarly, cohabitation was related among women to being a target of violence, as were having been abused as a child and scoring low in social desirability. Findings are related to those of other studies of dating abuse, as well as to the family violence and aggression literatures.

By now it is well-established that violence is an integral part of American family life (e.g., Straus, Gelles, \& Steinmetz, 1980). Yet because family violence researchers (e.g., Gelles, 1974) have tended to assume that violence seldom occurs in dating and courtship relationships, the potential for abuse among dat ing couples has received little attention until very recently. In the past few years, a handful of surveys on college campuses have begun the task of describing the nature and prevalence of physical violence in dating relationships. In the first such study, Makepeace (1981) revealed that on one campus one out of every five students had experienced at least one incident of abuse, ranging in severity from slapping and hitting to life-threatening violence. Cate, Henton, Koval, Christo-

${ }^{1}$ A version of this paper was presented at the meeting of the Southeastern Psychological Association, Atlanta, March 1983. Lee Sigelman and Richard Shuntich are thanked for their helpful comments.

${ }^{2}$ Requests for reprints should be forwarded to Carol K. Sigelman, Department of Psychology, 145 Cammack, Eastern Kentucky University, Richmond, KY 40475.

\section{0}

Journal of Applied Social Psychology, 1984, 5, 6, pp. 530-548.

Copyright (c) 1984 by V.H. Winston \& Sons, Inc. All rights reserved. pher, and Lloyd (1982) arrived at a similar figure, finding such violence to be reciprocal in two-thirds of the cases. Finally, Laner and Thompson (1982), expanding the inquiry to verbal abuse as well as physical abuse, reported that fully two-thirds of the students they surveyed had had at least one brush with violence.

While these surveys have outlined the basic dimensions of the problem, they have done little to identify predictors of involvement in violent episodes. One generalization that has clearly emerged is that the likelihood of aggression increases with the seriousness of the relationship (Cate et al., 1982; Laner \& Thompson, 1982). Indeed, family violence researchers Ylio and Straus (1981), after finding higher rates of physical aggression among cohabitating couples than among married couples, suggested that violence, rather than being a function of marriage itself, simply reflects the potential for intense conflict in any intimate relationship. If one takes this position, then one might expect the existing literature on family violence to be a fertile source of hypotheses about factors related to violence in premarital relationships.

While students of family violence (e.g., Gelles, 1980) concede that theory is in short supply, several researchers (e.g., Gelles, 1974; Straus et al., 1980) have argued that violence is rooted in the very fabric of society, particularly in cultural norms legitimizing violence and maintaining a sexist organization of society and the family. The point of departure for the present study is the notionembodied in the concept of a "subculture of violence" (Wolfgang \& Ferracuti, 1967) that some people are more prone to violence in heterosexual relationships than others are because norms sanctioning violence are more strongly endorsed in some subcultures than in others. From a social learning perspective, one would predict that an individual's likelihood of being involved in violent heterosexual relationships stems from socialization into norms supportive of violence in general-and violence in heterosexual and family relationships in particular. The latter norms would be expected to be more strongly supported to the extent that traditional norms of male dominance prevail and are threatened (e.g., see Allen \& Straus, 1979). The particular predictor variables chosen for the present study can be viewed as indicators of socialization into norms supporting violence, norms relevant to violence or to male dominance and sexism, or both.

Based on the family violence literature, one would predict that violence is linked to lower socioeconomic status, particularly low income (Straus et al., 1980), partly because norms legitimizing violence and male dominance are stronger in low income areas, and partly because low income is related to stress and frustration that may trigger violence. Although Laner and Thompson (1982) failed to support this hypothesis in their dating abuse study, the hypothesis still warrants further exploration. The existing literature also demonstrates that exposure to violence in childhood, through either direct experience or 
observational learning, disinhibits aggressive tendencies and reinforces violence as a means of conflict resolution and social control (Carroll, 1977; Flynn, 1977; Rosenbaum \& O'Leary, 1981). Flynn (1977), for example, found associations between both being abused as a child and witnessing violence between one's par. ents, on the one hand, and being either a victim or perpetrator of spouse abuse, on the other. In their dating abuse study, Laner and Thompson (1982) reported modest associations between having been abused as a child and both inflicting and experiencing violence, and suggested that the influence of having witnessed spouse abuse should be examined.

Socialization into norms related to sexism has received less attention than socialization experiences directly related to violence. Interestingly, the family violence literature reveals that husbands and wives abuse each other with roughly equal frequency (e.g., Straus et al., 1980), but witers have nonetheless speculated that both traditional sex roles and current shifts in sex-role attitudes may predispose marriage partners to violence (Hilberman, 1980; Walker, 1981). It is easy enough to understand how traditional sex-role socialization might predispose men to use aggression as a means of resolving conflicts or maintaining dominance. Burt (1980), for example, found men who engaged in high levels of sexrole stereotyping to be relatively accepting of violence in sexual relationships. Compared with more liberated men, those who hold conservative sex-role attitudes also tend to have higher needs for dominance and to be more threatened by women with strong achievement motivation (Greenburg \& Zeldow, 1977). Rosenbaum and O'Leary (1981) have provided limited but direct evidence that men who abuse their wives hold conservative attitudes toward women.

Meanwhile, traditional sex-role attitudes among women would presumably encourage dependency and passivity in the face of male violence; indeed, female dependency is correlated with abuse by one's spouse (Kalmuss \& Straus, 1982). More recently, however, family violence researchers have suggested that feminism, rather than traditional femininity, may also play a role in family violence. Focusing on power and status differentials within marital relationships. they have found that feminists are less satisfied than traditionalists with their relationships and are more given to confrontation in resolving conflicts (Wilson, 1982), and that violence is especially likely in marriages with status discrepancies, particularly when the wife's power in the relationship or occupational at tainment is high relative to her husband's, possibly because such imbalances directly threaten norms supporting male dominance (Allen \& Straus, 1979; Hornung, McCullough, \& Sugimoto, 1981).

All of this points to the potential fruitfulness of examining sex-role attitudes in relationship to dating abuse, with the expectation that among men highly traditional sex-role attitudes may be associated with engaging in violence, while among women highly traditional sex-role attitudes may predict being the target of violence and highly liberated attitudes may predict committing it. The recent family studies also hint that the degree of discrepancy between sex-role attitudes held by partners and/or the degrees of power each has in the relationship may predict violence, with violence being especially likely when sex-role attitudes clash (especially when traditional male and liberal female are matched) or power is lopsided.

Finally, if norms pertaining to violence and sex-roles do play a tole in dating violence, their effects should be most noticeable in areas of the country where such norms are still most strongly endorsed. Whereas previous studies of dating violence have been done in relatively liberal states, the present survey was conducted in the more traditionalistic Southeast; moreover, it included many students from rural Appalachian areas, where there is reason to expect traditionalism with regard to both violence and male dominance to be especially strong and to legitimize male aggression in heterosexual relationships (Gastil, 1971; Rogers \& Burdge, 1972; Willits, Bealer, \& Crider, 1974).

The primary objective of the present study is to move the study of violence in college students' relationships beyond description and into prediction. Based on the family violence literature, a prediction can be made that experience with heterosexual violence is more likely among students involved in serious, specifically cohabiting, relationships; among those from lower socioeconomic backgrounds; and among those who received or witnessed abuse as a child. Special attention is focused on the relationship between sex-role attitudes and violence, especially on the possibility that traditional views among men, and either highly traditional or highly liberated views among women, predispose them to involvement in violent episodes with partners, as well as to the possibility that socialization into a highly traditional subculture heightens the potential for abuse by men.

In addition, the present study was designed to supplement and clarify previous descriptive work on violence in dating relationships. Since only Laner and Thompson (1982) even reported sex differences in rates of violence, the present study systematically compares the reported behavior of men and women, both as aggressors and as victims. Because Makepeace (1981) raises the issue of response bias in the reporting of violence, a measure of socially desirable responding was included as a check on response bias, as well as a variable of substantive interest in view of evidence that low need for approval is related to aggression in a laboratory setting (Taylor, 1970). Finally, the study examines not only physical violence as it has been conceptualized by students of family and dating violence, but aggression that is explicitly sexual in nature. Sexual aggression, known for some time to be relatively common in college students' relationships (e.g., Kanin, 1967; Kirkpatrick \& Kanin, 1957; Koss \& Oros, 1982), has never been conceptualized as behavior potentially available to women as well as to men, nor has it been related to the types of physical violence of interest to family and dating abuse researchers. 


\section{Method}

\section{Participants}

Participants in the study were 504 university students who filled out a questionnaire on a voluntary, anonymous, and confidential basis. Questionnaires were distributed in psychology, sociology, and nursing classes at Eastern Kentucky University, a state school with approximately 13,000 students located on the edge of the Appalachian Mountain chain. The 116 males and 388 females in the sample represented $94 \%$ of those to whom the questionnaire was distributed. The sample included a heavy representation of nursing majors (36.4\%), along with students in law enforcement (8.2\%), undeclared majors (8.0\%), psychology majors $(6.6 \%)$, and a broad scattering of other liberal arts and education majors. Most were freshmen and sophomores (66.9\%), and the mean age was 21.4 . The majority of respondents were Caucasian $(89.3 \%) ; 18.1 \%$ were from rural areas, $47.6 \%$ from small towns and cities, and $34.2 \%$ from large cities or suburbs. Approximate family income was under $\$ 10,000$ for $9.9 \%, \$ 10,000$ to $\$ 19,999$ for $19.0 \%$; $\$ 20,000$ to $\$ 29,999$ for $28.4 \%$, and $\$ 30,000$ or more for $42.7 \%$. While this sample cannot be considered representative of the larger student population, the sampling procedure was consistent with those used in other studies of abuse in dating relationships.

\section{Questionnaire}

The questionnaire consisted of six sections. The first section requested demographic information. The second was the short form of the Attitudes toward Women Scale (AWS) developed by Spence and Helmreich (1972). The AWS measures views regarding the role of women in society, the privileges women ought or ought not to have, and beliefs about women. Like the original, the short form (Spence, Helmreich, \& Stapp, 1973) is a Likert-type scale, with each item having four response options ranging from strong agreement to strong disagreement. Item scores ranging from 0 to 3 are summed across the 25 items to yield a total score that can range from a highly traditionalistic 0 to a highly liberated or profeminist 75 . Spence et al. (1973) report that the short form correlates with the full form at 97 for both males and females. Yoder, Rice, Adams, Priest, and Prince (1982) report adequate internal consistency and test-retest reliabilities for the short form, and others (Kilpatrick \& Smith, 1974; Lunneborg, 1974) have provided evidence that the AWS has satisfactory construct validity.

The third section of the questionnaire was the Social Desirability Scale (Crowne \& Marlow, 1964). The scale, which measures the tendency to describe oneself in favorable or socially desirable ways, includes statements that are cul- turally acceptable but probably untrue and statements that are generally true but undesirable. Scoring of the 33-item scale involves adding points given for responses keyed in a socially desirable direction, with scores potentially ranging from 0 to 33 (maximum social desirability).

The final three sections of the questionnaire dealt with abuse. First, respondents completed a modified version of the Conflict Tactics Scale (Straus, 1979), various adaptations of which have been widely used in studies of premarital and family violence. The modified version used here assessed whether respondents had ever experienced the eight Straus Form $\mathrm{N}$ items describing physically aggressive acts (see Table 1), both as perpetrator and as recipient, in a heterosexual relationship. Response options were reduced from eight to three (never, once, more often). Two additional behaviors, both relating to sexual aggression, were also asked about in this section, using the same format as in the Conflict Tactics Scale: "used strong physical force to try to engage in a sex act against other's will" and "used violence to try to engage in a sex act against other's will." The two phrasings were intended to convey moderate and severe aggression, respectively. This section also asked how many of the ten types of abuse the respondent had undergone as a child and had witnessed in his or her parents' relationship.

The fifth section was answered only by those who reported some involvement in violent heterosexual relationships, as either perpetrator or recipient. It focused on the most recent relationship in which abuse had occurred, repeating the Conflict Tactics Scale items as they pertained to that relationship and exploring other characteristics of the relationship (the stage when abuse first occurred, the current status of the relationship, reasons for its termination, and the respondent's attitude toward the abuse).

Finally, the last section continued to ask respondents involved in abuse about their most recent abusive relationship while asking other respondents about a current dating relationship. It centered on the respondent's age at the onset of the relationship, the length of the relationship, the partner's educational status, the seriousness of the relationship, the power balance between partners, the respondent's overall evaluation of the relationship, and the respondent's and the partner's degrees of traditionality regarding what both men and women should be like (rated on ten-point scales).

\section{Results}

\section{Rates of Physical Abuse}

Overall, $53.6 \%$ of the male respondents and $52.1 \%$ of the female respondents reported having committed at least one of the eight physically abusive acts at some time in a heterosexual relationship. More men than women said that they 
Table 1

Percentages Reporting Some Involvement in Eight Abusive Acts in Their Heterosexual Relationships

\begin{tabular}{|c|c|c|c|c|}
\hline \multirow[b]{2}{*}{ Act } & \multicolumn{2}{|c|}{ Abuser } & \multicolumn{2}{|c|}{ Abusee } \\
\hline & Male & Female & Male & Female \\
\hline Threw something & 18.0 & 27.0 & 31.2 & 19.5 \\
\hline Pushed, shoved & 42.3 & 28.8 & 37.5 & 42.3 \\
\hline Slapped & 17.1 & 34.5 & 39.3 & 20.4 \\
\hline Kicked, hit, bit & 9.0 & 18.4 & 27.7 & 13.3 \\
\hline \multicolumn{5}{|l|}{ Hit (or tried) with } \\
\hline something & 11.8 & 18.6 & 24.1 & 15.6 \\
\hline Beat up & 2.7 & 1.3 & 3.6 & 3.6 \\
\hline \multicolumn{5}{|l|}{ Threatened with } \\
\hline knife/gun & 1.8 & 1.3 & 2.7 & 3.1 \\
\hline Used knife/gun & 0.6 & 0.6 & 0.0 & 0.8 \\
\hline
\end{tabular}

Note: $N$ s for males range from 110 to $112 ; N$ for females from 379 to 384.

had been the target of at least one such act, $58.9 \%$ versus $47.8 \%\left(\chi^{2}(1)=4.31\right.$, $p<.05)$.

Table 1 reports the percentas $a_{5}$ of men and women who indicated that they had perpetrated or been victimized by each specific act. The data, of course, indicate only the reporting of some experience with an act, not the seriousness of particular instances of an act or frequency of involvement. The table makes it apparent that milder forms of physical aggression-pushing or shoving, slapping, and throwing things--are more common than are more serious acts. The table also reveals both similarities and differences between men and women, as well as several striking correspondences between reports of acts committed by members of one sex and reports of acts received by members of the opposite sex. Analyses of sex differences revealed that women were more likely than men to slap partners $\left(\chi^{2}(1)=12.31, p<.001\right)$; corroborating them, males were more likely than females to report having been slapped $\left(\chi^{2}(1)=16.70, p<.0001\right)$. Women also said that they had done more kicking, hitting, or biting $\left(\chi^{2}(1)=5.58, p<\right.$ $.05)$, and men corroborated this by indicating that they more often than women had been the targets of such behavior $\left(\chi^{2}(1)=12.93, p<.001\right)$. Finally, somewhat more women than men claimed to have thrown things at partners $\left(\chi^{2}(1)=\right.$ $3.68, p<.06)$; more men than women reported having had things thrown at them $\left(\chi^{2}(1)=6.90, p<.01\right)$.
Other sex differences were not as firmly corroborated by members of the opposite sex, although trends were in the proper directions. More men than women claimed to have pushed or shoved partners $\left(\chi^{2}(1)=7.27, p<.01\right)$, but women were only somewhat more likely than men to have been the targets of such behavior. Men were also more likely than women to report having been hit (or missed) with objects $\left(\chi^{2}(1)=4.31, p<.05\right.$ ).

Thus, women appear to be more likely than men to slap; kick, hit, or bite; and throw things at partners. Men appear to be more likely than women to engage in only one form of violence: pushing or shoving. Despite the absence of an overall significant difference between the sexes in commission of at least one form of physical aggression, then, it is women rather than men who show the greater tendency to engage in some of the more serious forms of violence. This impression is verified by examination of the last five acts on the list, which are the most severe and infrequent. Not only have more women than men engaged in at least one of these acts, $26.4 \%$ versus $16.4 \%\left(\chi^{2}(1)=4.62, p<.05\right)$, but men more frequently report having been the target of at least one such act, $34.8 \%$ versus $20.9 \%\left(\chi^{2}(1)=9.21, p<.01\right)$. It should also be noted that while absolute rates of committing various acts by males closely match female's rates of having been the targets of such acts, women's rates of reporting acts tend to be lower than the corresponding male reports of being victimized by such acts.

Physical abuse in dating relationships was often mutual. For both men and women, having physically abused a partner in some way was strongly related to having been physically abused in some way (for men, $\chi^{2}(1)=44.41, p<.0001$; for women, $\left.\chi^{2}(1)=143.57, p<.0001\right)$. Among men, $47.3 \%$ had both abused partners and been abused by partners, while $34.5 \%$ were neither perpetrators nor recipients; corresponding figures for women were $40.2 \%$ and $40.5 \%$, respectively. Of the respondents of both sexes who reported some experience with physical abuse, fully $67.3 \%$ had both committed it and received it rather than only one or the other.

Additional questions answered by those reporting some involvement in abuse, as either perpetrator or recipient, about their most recent abusive relationship shed further light on the abuse phenomenon. Among the 215 respondents who completed the section on their most recent abusive relationship, the mean number of the eight acts committed by the respondent was 1.88 , while the mean number committed by the partner was 1.80 . The actual number of different acts committed was zero for $15.8 \%$, one for $36.3 \%$, two to four for $41.4 \%$, and five or more for $6.5 \%$; corresponding percentages for reports of numbers of different acts by partners were $22.8 \%, 29.8 \%, 38.6 \%$, and $8.8 \%$. These figures suggest that most relationships involving abuse involve relatively little of it.

As in past studies, the vast majority (74.0\%) of relationships with abuse were beyond the "casual dating" stage and into either the "serious dating" stage or beyond (i.e., engagement, cohabitation) when the violence commenced. Follow- 
up questions also revealed that abuse reported by college students is not necessarily a campus phenomenon. Overall, $37.0 \%$ of the partners in abusive relation. ships were students at the same university as the respondent at the time of the relationship; another $19.4 \%$ were students at other colleges or universities; $21.3 \%$ were high school students; and $22.3 \%$ were nonstudents. This breakdown of partner's educational status was not significantly different from the one pertaining to the current relationships of students who were not involved in any abusive relationship. Indeed, descriptions of abusive relationships were generally similar to descriptions of nonabusive current relationships. Respondents reporting on their most recent violent relationship did, on the average, evaluate that relationship more negatively on an eight-point scale $(M=3.67$, where 3 is "very good" and 4 is "good") than did students characterizing nonabusive relationships ( $M=$ 3.31 ), $F(1,458)=4.97, p<.05$, but their mean response nonetheless fell in the positive portion of the scale. Moreover, $53.7 \%$ of these relationships were ongoing at the time of the survey, and among those whose abusive relationships had ended, only $13.6 \%$ attributed the breakup entirely to the abusive behavior, with another $33.0 \%$ implicating abuse along with other reasons. Finally, on a five-point scale, $66.9 \%$ judged their own abusive behavior either "somewhat justified" or "very justified," and $43.4 \%$ conceded that their partner's acts were at least "somewhat justified."

\section{Sexual Violence}

The two questions about sexual aggression were combined due to low rates of involvement in the more violent of the two forms of sexual aggression. As ex. pected, more men than women admitted to such behavior, $11.8 \%$ versus $1.8 \%$ $\left(\chi^{2}(1)=21.61, p<.001\right)$; concomitantly, more women than men had been the targets of sexual aggression, $34.8 \%$ versus $20.9 \%\left(\chi^{2}(1)=9.21, p<.01\right)$. It is noteworthy that both sexes reported being the victim of such behavior more often than the opposite sex reported committing it. It is also noteworthy that relationships between involvement in sexual abuse and involvement in physical abuse tended to be relatively weak, though significant. Among men, there was a small but significant association between having been sexually aggressive toward a partner and having been physically aggressive $\left(\chi^{2}(1)=5.52, p<.01\right)$. However, only $10.1 \%$ had committed both types of acts, compared with $44.0 \%$ who had committed neither and $44.0 \%$ who had engaged in physical but not sexual aggression. Among men, the relationship between having been sexually and physically abused fell short of significance $\left(\chi^{2}(1)=3.18, p<.10\right)$. Women reported having committed sexual aggression too rarely to permit analysis; however, a greater proportion of victims of physical abuse than of nonvictims of physical abuse also claimed to have been sexually abused by partners, $45.3 \%$ versus $19.1 \%\left(\chi^{2}(1)=30.13, p<.0001\right)$.

\section{Predictions of Involvement in Physical Abuse}

Separate analyses for male and female respondents were conducted to determine which of several predictors were related to both abusing a partner and being abused by a partner at some time via one or more of the eight physically violent acts listed in Table 1 . The eight predictors were age; family income (measured on a four-point scale with income ranges of $\$ 10,000$ each, up to $\$ 30$; 000 and above); AWS score; social desirability score; having witnessed abuse in one's parental relationship ( 0 or 1 ); having been abused as a child ( 0 or 1$)$; currently living with a member of the opposite sex, either unmarried or married ( 0 or 1$)$; and currently residing in a federally defined Appalachian county ( 0 or 1 ). Because the dependent variables were dichotomous (not involved vs, involved in physical abuse), discriminant analysis was used to determine each predictor's independent contribution to abuse involvement and the entire set of predictors' ability to differentiate between respondents involved and uninvolved in abuse.

As a preliminary to the discriminant analyses, product-moment correlations were computed between the eight predictors and each of the four dependent variables. The correlations, shown in Table 2 , are generally weak and attain statistical significance more often in the large female sample than in the smaller male sample. Nonetheless, they suggest the following: (1) among women, both abusing and being abused by partners tend to be associated with being older, having a low tendency toward socially desirable responding, having witnessed parents abusing each other, being abused by one's parents as a child, and living with a man; and (2) among men, both abusing and being abused are associated with a low family income and living with a woman, while inflicting abuse is further related to having traditional attitudes toward women and an Appalachian residence, with Appalachian men, as expected, being somewhat less liberal in their sex-role attitudes than non-Appalachian men $(r=-.18, p<.05)$. Living with a member of the opposite sex was the most consistent predictor across abuse involvement measures.

Since simple correlations leave the impacts of other predictors uncontrolled, it is necessary to examine the outcomes of the discriminant analyses in Table 3 to assess the independent contributions of individual predictors. Table 3 summarizes the four discriminant analyses, presenting standardized discriminant function coefficients, which indicate the relative contributions of the predictors in discriminating abuse-nonabuse status. Positive signs indicate a positive relationship between a variable and either abusing or being abused. Table 3 also presents the canonical correlation for each analysis-a measure of the ability of the entire set of independent variables to predict abuse status-as well as the statistical significance of each prediction equation. Also provided for each analysis is the percentage of cases correctly classified as involved or uninvolved in abuse, and the tau statistic, which can be interpreted as the percent of error reduction 
Table 2

Simple Correlations Between Predictor Variables and Involvement in Abuse

\begin{tabular}{|c|c|c|c|c|}
\hline & \multicolumn{2}{|c|}{ Abuser } & \multicolumn{2}{|c|}{ Abusee } \\
\hline & Male & Female & Male & Female \\
\hline Age & $=06$ & $.11^{*}$ & .11 & $.09^{*}$ \\
\hline Family income & $26 *$ & -.03 & $-.19^{*}$ & $-10^{8}$ \\
\hline AWS & $-.19 \%$ & .06 & .02 & .03 \\
\hline Social desirability & -06 & $.20^{* * * 8}$ & -.13 & $-.14^{* *}$ \\
\hline Witnessed parent & & & & \\
\hline abuse & .05 & $.14^{\text {*a* }}$ & .06 & $.14 * *$ \\
\hline Abused as child & .13 & $.17^{8 * 2 * 2 \pi}$ & .08 & $20 * * *$ \\
\hline Cohabitation & $.18^{*}$ & $.11^{8}$ & $.19^{*}$ & $.23^{* * *}$ \\
\hline Appalachian & $.17^{*}$ & .05 & .12 & .06 \\
\hline
\end{tabular}

Note: $N$ s for males range from 97 to 111 and $N$ s for females from 338 to 381 . ${ }^{*} p<.05$.

$* * p<.01$.

$* * * p<.001$.

achieved by the prediction equation relative to the error rate that would be expected if participants were randomly assigned to abuse or nonabuse categories in proportion to the actual numbers of cases in the two categories. Finally, the statistical significance of the contribution made by individual predictors was determined by a serial deletion procedure in which the difference between the $\chi^{2}$ for the full eight-predictor model and the $\chi^{2}$ for a seven-predictor model with a given predictor omitted is itself a $\chi^{2}$ indicative of the independent contribution of that predictor.

To what extent can one predict which men will be abusive? While $67.98 \%$ of the men could be correctly classified as abusers or nonabusers, and this represented a $34 \%$ reduction in error below the chance error rate, the overall prediction model fell just short of significance. Standardized coefficients suggest that males who abuse partners tend to be relatively young, low in family income $\left(\chi^{2}(1)=3.05, p<.10\right)$, traditionalistic in their attitudes toward women, abused as children, currently living with a woman, and from an Appalachian county. However, none of these individual predictors made a significant contribution to the prediction of abuse.

In the larger female sample, a woman's status as an abuser or nonabuser could
Table 3

Summary of the Discriminant Analyses Predicting Abuse Involvement

\begin{tabular}{|c|c|c|c|c|}
\hline & \multicolumn{2}{|c|}{ Abuser } & \multicolumn{2}{|c|}{ Abusee } \\
\hline & Male & Female & Male & Female \\
\hline \multicolumn{5}{|c|}{ Standardized coefficients } \\
\hline Age & -.41 & .13 & -.31 & -.23 \\
\hline Family income & -.55 & .13 & .61 & -.01 \\
\hline AWS & -.46 & .04 &. .19 & -.15 \\
\hline Social desirability & .18 & $-.58 *$ & .03 & $\cdot 37 *$ \\
\hline Witnessed abuse & $=04$ & .22 & .33 & .22 \\
\hline Abused as child & .38 & $.56^{*}$ & +17 & $.44^{*}$ \\
\hline Cohabitation & .49 & .32 & $.74 *$ & $.79 *$ \\
\hline Appalachian home & .46 & $-.45 *$ & .17 &. .00 \\
\hline Canonical correlation & .41 & .30 & .35 & .36 \\
\hline$x^{2}$ & 13.45 & 27.69 & 10.00 & 42.01 \\
\hline$p$ & $<.10$ & $<.001$ & $<30$ & $<.0001$ \\
\hline \multicolumn{5}{|l|}{$\%$ classified cor- } \\
\hline tau & .34 & .26 & .25 & .31 \\
\hline$N$ & 81 & 302 & 83 & 301 \\
\hline
\end{tabular}

"Significant at the .05 level or beyond.

be predicted beyond chance expectation, with $63.25 \%$ of the cases correctly classified. Three predictors made significant independent contributions. Females who reported abusing partners were likely to score low in social desirability $\left(\chi^{2}(1)=8.78, p<.01\right)$, to have been abused as children $\left(\chi^{2}(1)=7.54\right.$, $p<.01)$, and to come from a non-Appalachian area $\left(\chi^{2}(1)=4.86, p<.05\right)$.

Which men had been abused by their partners? Again, the overall prediction equation for males fell short of statistical significance, but men who were living with a woman were more likely to have been targets of abuse than those not doing so $\left(\chi^{2}(1)=4.27, p<.05\right)$. Coming from a lower income family also appeared to be related to being abused, but the relationship was not significant $(\rho<.10)$. The analysis predicting which women had been abused by partners was similar. Here the ability of the model to predict abusee status was significant, and the strongest individual predictor, as with men, was living with a mem- 
ber of the opposite sex $\left(\chi^{2}(1)=18.96, p<.001\right)$. Having been abused as a child was also related to being abused by partners $\left(\chi^{2}(1)=7.02, p<.01\right)$, and again, there were signs that low socially desirable responding was associated with reporting involvement in abuse $\left(\chi^{2}(1)=5.32, p<.05\right)$.

Looking across the four discriminant analyses, several patterns seem clear. First, it is not easy to predict involvement in abuse. Even in the larger female sample, where relationships were statistically significant, the percentages of cases correctly classified as involved or uninvolved in abuse were modest. As for the specific predictors, age had little impact, except that younger men tended to be more abusive. Low family income appeared to be more related to male involvement in abuse $(p<.10)$ than to female involvement in abuse. Attitude toward women, a construct of central interest in this study, was generally unrelated to involvement in abuse, but showed its greatest promise as a predictor of abuse by men, with more traditionalistic men, as predicted, being somewhat, but not significantly, more prone to abusing partners. Meanwhile, among women, socially desirable responding proved to be a significant predictor of reporting never having abused nor having been abused by a partner. In addition, having been abused as a child proved to be more useful as a predictor of dating abuse than did having seen one's parents abuse one another, and was significantly predictive of female involvement in abuse. Moreover, there was evidence that the high traditionalism of Appalachian culture is associated with a weak tendency toward inflicting abuse among men coupled with a significant tendency toward refraining from such abuse among women. Finally, of all the predictors, living with a member of the opposite sex proved to be the most powerful, significantly predicting being the target of abuse for both men and women and also being positively but more weakly associated with inflicting abuse in both sexes.

\section{Additional Explorations of Sex-Role Issues}

The Attitudes toward Women Scale proved to be only a weak predictor of involvement in abuse, although the relationship between male traditionalism and perpetration of abuse warrants further exploration. The possibility that relation. ships were curvilinear in form had been explored and ruled out before the linear techniques reported were applied; moreover, it was established that there was no socially desirable response bias on the AWS in either sex. Left to examine, how. ever, was the possibility that attitudinal discrepancy between partners enhances the potential for violence. The present study included ten-point scales measuring traditionalism with respect to both male and female roles on the part of both the respondent and a partner described by the respondent. These scales were used to form a score representing the signed difference between self and partner in attitudes toward women and a parallel score pertaining to attitudes toward men. These scores were then collapsed into five categories (male is five or more scale points more liberal or modern than his partner, male is two to four points more modern, partners are within one point of each other, female is two to four points more modern, or female is five or more points more modern than her partner).

In data supplied by men, there were no significant relationships between these scores and the likelihood of either physically abusing or being physically abused by one's partner, although men who were more traditional in attitudes toward women than their partners were tended to be more likely to commit physical abuse in the relationship than other men were $(p<.11)$. Among women, there was a significant curvilinear relationship between having abused one's partner and self-partner discrepancy in attitudes regarding women $\left(\chi^{2}(4)=\right.$ $14.26, p<.01)$. Women were more likely to have abused their partners if those partners, relative to themselves, were either considerably more traditionalistic $(58.5 \%)$ or considerably more liberal $(57.1 \%)$ than if the self-partner discrepancy scores were intermediate between these two extremes $(20.0,37.9$, and $37.0 \%$, respectively). Women also tended to be more likely to end an abusive relationship if they were either much more liberal or much more traditional in their stance on the role of women than their partners were than if self and partner attitudes were more congruent, but the relationship was nonsignificant $(p<.06)$.

Finally, the relationship of the power allocation or dominance pattern within the relationship to abusing and being abused was explored using a five-point scale asking which partner dominated the relationship. While this dominance variable was unrelated to abuse among men, men tended to be more likely to abuse and to be abused when the power balance was lopsided rather than equal. Among women, this curvilinear relationship was significant for both abusing $\left(\chi^{2}(4)=13.43, p<.01\right)$, and being abused $\left(\chi^{2}(4)=13.00, p<.05\right)$. Percentages of women in the sample who abused their partners-moving from relationships with almost complete female dominance through equality to almost complete male dominance-were $83.3 \%, 41.3 \%, 32.3 \%, 47.1 \%$, and $57.1 \%$; parallel percentages reporting having been abused by that partner were $50.0 \%, 34.8 \%$, $25.8 \%, 44.1 \%$, and $50.0 \%$.

\section{Discussion}

Although direct comparisons of studies of violence in the relationships of college students are hampered by differing items and methods of reporting rates of abuse, all signs indicate that the present study's rates, the first obtained in the southeastern part of the United States, are higher than previously reported rates. Only Laner and Thompson (1982) reported more widespread involvement, and this is attributable largely to their inclusion of a verbal abuse item, which more than half of their respondents endorsed. Comparisons of rates for 
specific acts-particularly comparisons with the Cate et al. (1982) data based on seven of the eight Straus items used here-confirm the impression that rates of experience with violence in the present study were high and imply that subcultural context has a bearing on the prevalence of physical violence in the relation. ships of college students.

The present study offers the first systematic examination of sex differences in abusive behavior. While neither sex was more likely to be abusive overall, women were more likely to slap; kick, hit, or bite; and throw things at partners. Indeed, women showed the greater proneness toward the more serious acts examined, with men being more likely than women to commit only acts involy. ing pushing or shoving (see Straus et al., 1980). These findings have a parallel in laboratory research showing that men are more likely than women to be given shocks in mixed-sex confrontations (Taylor, 1967; Shuntich \& Shapiro, 1982). At the same time, men were more likely to commit aggression in the context of sexual behavior, and this form of aggression proved to be only modestly, though significantly, related to physical violence.

It is important to qualify this picture of violence in relationships, however, by noting that most instances of violence were mild, isolated, and inconsequential for the relationship. It was for this reason that the major analyses reported here centered on the simple presence or absence of violence rather than on its frequency and intensity. The milder forms of violence studied here have been termed "normal violence" by Straus et al. (1980) due to their normative support within the family. Widespread support for such violence in dating relationships might account for its being perceived as justifiable and as no reason to end a relationship. While it would be useful in further research to dist inguish between violence that is perceived as "normal" and violence that is clearly unacceptable and offensive, we, like Straus and his colleagues, find noteworthy the fact that violent acts that would be abhorrent in peer or colleague relationships appear to have acquired legitimacy in heterosexual relationships. Moreover, our own attempts to predict involvement in only the five most serious acts in Table 1, unreported here, suggested that the difference between them and the milder acts is more a matter of degree than of different dynamics. At the same time, we would warn that the present findings do not focus on, and may not generalize to, that subset of dating relationships in which abuse is intense and pervasive.

While our ability to predict who inflicts and who receives violence was limited, especially in the smaller male sample, several interesting relationships emerged. Like Laner and Thompson's (1982) dating abuse study and several studies of family abuse, the present study linked involvement in abuse to having been abused as a child, though here the relationship was significant only for women. The findings also support Laner and Thompson in that abuse was largely unrelated to age and indicators of family socioeconomic status, though here there were near significant associations for men between abuse involvement and low family income. In addition, the present findings support those of both Laner and Thompson (1982) and Cate et al. (1982) by suggesting that abusive behavior is more likely in serious than in casual relationships. This link was implied by the fact that relationships with violence were generally in at least a serious dating phase before violence began, but was most evident in the fact that living with a member of the opposite sex, married or unmarried, was the strongest and most consistent predictor of involvement in abuse, especially of being a target of abuse. It is unclear whether intimacy is directly related to violence or whether it merely provides more opportunities for violence to occur. If living with someone is viewed as a situational influence on heterosexual violence, its importance here suggests the need for further attention to the types of variables not examined here, the situational and contextual factors within dating relationships that either trigger or inhibit violence (e.g., alcohol use, patterns of communication, situational stressors; see, for example, Laner's, 1983, extension of research on the role of alcohol in family violence to the dating domain).

Correlational and discriminant analyses also offered a methodological warning about research on this sensitive topic: the possibility that socially desirable responding, especially among women, leads to underreporting of experience with abusive behavior. The fact that men in the study tended to report being the targets of abuse more often than women reported inflicting it supports the notion of response bias in women's responses. However, it is also possible that personality characteristics associated with socially desirable responding are also associated with avoiding abusive relationships or behavior. Taylor's (1978) finding that persons low in social desirability are more likely to administer shocks to partners than are persons high in social desirability adds credibility to this interpretation, particularly if a low need for social approval implies weakened inhibitions against antisocial behavior. The relationship between social desirability and aggression surely warrants further exploration.

Finally, our attempt to examine relationships between sex-role attitudes and involvement in abuse failed to establish a strong association. While correlational analysis indicated that men with low scores on the Attitudes toward Women Scale were more likely to have abused partners than were more liberated men, the relationship faded in the discriminant analyses when other variables were controlled. At the same time, supplementary analyses of specific relationships with and without violence suggested that, for women at least, committing violence was more likely in relationships with discrepancies in attitudes toward women and power imbalances than in more equalitarian relationships. These findings, while only partially consistent with relevant data from studies of family violence (e.g., Allen \& Straus, 1979), are intriguing, for they hint that it matters less who is more liberated or who holds more power in a male-female relationship than that a discrepancy in sex-role attitudes or a power imbalance exists. In addition, residence in Appalachia, which has been linked to both traditional 
sex-role views and the internalization of norms of violence, was positively but weakly associated for men with inflicting abuse and significantly associated for females with refraining from it. Collectively, these findings point to the potential value of measuring the sex-role attitudes and power relationships of actual dating partners and then focusing attention on the issue of partner compatibility.

It is by now firmly established that physical violence occurs with some frequency in relationships involving college students. What is needed now is further examination of factors that can account for why some students are involved in abusive relationships and others are not, factors that might differentiate between relationships with only minor violence and relationships with serious and perpetual violence, factors that can explain how dating violence is similar to and different from marital violence, and factors that tie violence to the dynamics of particular heterosexual relationships.

\section{References}

Allen, C.M., \& Straus, M.A. (1979). Resources, power, and husband-wife violence. In M.A. Straus \& G.T. Hotaling (Eds.), The social causes of husbandwife violence. Minneapolis: University of Minnesota Press.

Burt, M.R. (1980). Cultural myths and support for rape. Journal of Personality and Social Psychology, 38, 217-230.

Carroll, J.C. (1977). The intergenerational transmission of family violence: The long term effects of aggressive behavior. Aggressive Behavior, 3, 289 . 299.

Cate, R., Henton, J., Koval, J., Christopher, F.S., \& Lloyd, S. (1982). Premarital abuse: A social psychological perspective. Journal of Family Issues, 3, 79. 80.

Crowne, D., \& Marlowe, D. (1964). The approval motive. New York: Wiley.

Flynn, J. (1977). Recent findings related to wife abuse. Social Casework, 40, 13.20.

Gastil, R.D. (1971). Homicide and a regional culture of violence. American Sociological Review, 36, 412-427.

Gelles, R.J. (1974). The violent home: A study of physical aggression between husbands and wives. Beverly Hills, CA: Sage.

(1980). Violence in the family: A review of research in the seventies. Journal of Marriage and the Family, 42, 873-885.

Greenburg, R.P., \& Zeldow, P.B. (1977). Personality characteristics of men with liberal sex-role attitudes. Journal of Psychology, 97, 187-190.

Hilberman, E. (1980). Overview: The "wife-beater's wife" reconsidered. American Journal of Psychiatry, 11, 1336-1347.

Hornung, C. A, McCullough, B.C., \& Sugimoto, T. (1981). Status relationships in marriage: Risk factors in spouse abuse. Journal of Marriage and the Family, 43, 675-692.

Kalmuss, D.S., \& Straus, M.A. (1982). Wife's marital dependency and wife abuse. Journal of Marriage and the Family, 44, 277-286.

Kanin, E.J. (1967). An examination of sexual aggression as a response to sexual frustration. Journal of Marriage and the Family, 29, 428-433.

Kilpatrick, D.G., \& Smith, A.D. (1974). Validation of the Spence-Helmreich Attitudes towards Women Scale. Psychological Reports, 35, 461-462.

Kirkpatrick, C., \& Kanin, E. (1957). Male sex aggression on a university campus. American Sociological Review, 22, 52.58.

Koss, M.P., \& Oros, C.J. (1982). Sexual experiences survey: A research instrument investigating sexual aggression and victimization. Joumal of Consulting and Clinical Psychology, 50, 455-457.

Laner, M.R. (1983). Courtship abuse and aggression: Contextual aspects. Sociological Spectrum, 3, 69-83.

\& Thompson, J. (1982). Abuse and aggression in courting couples. Deviant Behavior, 3, 229-244.

Lunneborg, P.W. (1974). Validity of Attitudes toward Women Scale. Psychological Reports, 34, 1281-1282.

Makepeace, J.M. (1981). Courtship violence among college students. Family Relations, 32, 97-102.

Rogers, E.M., \& Burdge, R.J. (1972). Social change in rural societies (2nd ed.). Englewood Cliffs, NJ: Prentice-Hall.

Rosenbaum, A., \& O'Leary, K.D. (1981). Marital violence: Characteristics of abusive couples. Journal of Consulting and Clinical Psychology, 49, 63-71.

Shuntich, RJ., \& Shapiro, R. (1982, April). Explorations of affection and aggression. Paper presented at the meeting of the Eastern Psychological Association, Baltimore, MD.

Spence, J.T., \& Helmreich, R. (1972). The Attitudes toward Women Scale: An objective instrument to measure attitudes toward the rights and roles of women in contemporary society. JSAS Catalog of Selected Documents in Psychology, 2(66).

Spence, J., Helmreich, R., \& Stapp, J. (1973). A short version of the Attitudes toward Women Scale (AWS). Bulletin of the Psychonomic Society, 2, 219. 220 .

Straus, M.A. (1979). Measuring intra-family conflict and violence: The Conflict Tactics (CT) Scales. Journal of Marriage and the Family, 41, 75.88.

Straus, M.A., Gelles, R.J., \& Steinmetz, S.K. (1980). Behind closed doors. Violence in the American family. New York: Anchor/Doubleday.

Taylor, S.P. (1967). Aggression as a function of the interaction of the sex of the aggressor and the sex of the victim. Journal of Personality, 35, 474 485 . 
Taylor, S.P. (1970). Aggressive behavior as a function of approval motivation and physical attack. Psychonomic Science, 18, 195-196.

Walker, L.E. (1981). Battered women: Sex roles and clinical issues. Professional Psychology, 12,81-91.

Willits, F.K., Bealer, R.C., \& Crider, D.M. (1974). The ecology of social tradi. tionalism in a rural hinterland. Rural Sociology, 39, 334-349.

Wilson, G.D. (1982). Feminism and marital dissatisfaction. Personality and Individual Differences, 3, 345-347.

Wolfgang, M.E., \& Ferracuti, F. (1967). The subculture of violence. London: Tavistock.

Yllo, K., \& Straus, M.A. (1981). Interpersonal violence among married and cohabitating couples. Family Relations, 30, 339-347.

Yoder, J.D., Rice, R.W., Adams, J., Priest, R.F., \& Prince, H.T. (1982). Reliability of the Attitude toward Women Scale (AWS) and the Personal Attributes Questionnaire (PAQ). Sex Roles, 8, 651-657. 